\title{
Development of State Space Model and Control Design of Two-Mass System Using Standard Forms
}

\author{
Ghazanfar Shahgholian, Afshin Etesami, \\ Mohammad Reza Yousefi \\ Department of Electrical Engineering, \\ Najafabad Branch, Islamic Azad University, \\ Esfahan, Iran \\ shahgholian@iaun.ac.ir,mr_yousefi@iaun.ac.ir, \\ a_etesami@iaun.ac.ir
}

\author{
Farshad Mogharrab Tehrani \\ Department of Electrical Engineering, \\ Naghshejahan Higher Education Institute, \\ Esfahan, Iran \\ farshad_2003_sh@yahoo.com
}

\begin{abstract}
This paper presents dynamic analysis of a two-mass system using speed controller. In order to improve the dynamic performance, a modified PID (MPID) controller is suggested and compared with only PID controller. The coefficient diagra$m$ method (CDM) technique is applied to design controllers in two-mass system. The dynamic analysis is verified by transfer function simulation using Matlab and time domain simulation of the two-mass system. It is seen that the control system has fast speed response and robust stability.
\end{abstract}

Keywords- two-mass resonant system; coefficient diagram method; speed control.

\section{INTRODUCTION}

A rotary system having its rotating components coupled by a long and deflective shaft usually experiences torsional resonance. Vibration suppression and disturbance rejection control in torsional system is an important problem in the future motion control. Mechanical system with physical structure rendering torsional resonance is commonly encountered in industry. Mechanical resonance is usually caused by a combination of high servo gains and a compliant coupling between the motor and load. A mechanical system composed of some masses connected with flexible shaft is called multimass resonant system. The dynamic performances of speed and position controlled multi-mass driving system can be deteriorated especially due to the elastic coupling, non-linear friction and backlash. The mechanical system in the industrial motor drive can be modeled by a multi-mass system. The simplest model of such resonant mechanical system is two-mass system [1].

Control problem of a two-mass drive system is especially difficult when not all system variables are measurable. To overcome the problems, various control strategies have been proposed mainly for controlling two-inertia system [2, 3]. In [4] three kinds of typical pole assignments with identical radius/damping coefficient/real part are applied and compared, and the merits of each pole-assignment design are concluded. This method can slightly improve the damping ability of the drive, but the system dynamics decreases at the same time. In [5] an I-P controller is designed for a higher-order plant by using the concept of plant model reduction and the CRA method with the appropriate values of characteristic ratios in order to obtain the closed-loop step response without overshoot. A systematic comparative study of compensation schemes such as resonance ratio control and PID control for the coordinated motion control of two inertia mechanical systems is presented in [6]. In [7], the systematic analysis of two-inertia stabilization system is proposed, and an optimal controller to achieve better reference trackin$\mathrm{g}$ and disturbance rejection performance is introduced by pole assignment using ITAE criterion. A simple digital filter which cuts the resonant frequency proposed in [8], where the controller is effective for command responses but it is not able to suppress the vibration prompted by disturbance actively. The speed control using two-degrees-of-freedom (TDOF) controller for vibration suppression and the disturbance rejection based $\mathrm{H}_{\infty}$ control theory is presented in [9].

In the design of a linear time-invariant control system using the classical control theory, the first step is to choose the controller type. In most cases, the cost of control systems increases with its complexity. The conventional PID is widely used in most servo applications such as actuation, robotics, machine tools, and so on. They are easy to adjust and configure, in addition to providing possibilities of improvement in operation and control. Many control systems have been designed successfully using CDM. Comparing designs done by CDM and other design methods, it is seen that CDM can give a controller design which is both stable and robust, and it has the desired system response speed. Also, CDM is less sensitive to disturbances and bounded uncertainties resulted from parameter variations. Therefore CDM is an important method for controller design.

The main aim of this paper is dynamic modeling and develops an algorithm to design a speed control strategy for a two-mass resonant system. Also the study the applicability of PID type in dynamic performance enhancement with eigenvalue analysis is shown.

\section{Mathmatical Model OF Two-Mass System}

Fig. 1 shows a schematic of a two-mass resonant system consisting of two lumped inertias $\mathrm{J}_{\mathrm{M}}$ and $\mathrm{J}_{\mathrm{L}}$, representing the motor and load, respectively, coupled via a shaft of finite stiffness $K_{S}$, that is subject to torsional torque $T_{S}$ and excited by a combination of electromagnetic torque $T_{M}$ and load- 
torque perturbations $\mathrm{T}_{\mathrm{L}}$. Generally, the speed $\omega_{\mathrm{M}}$ and position $\theta_{\mathrm{M}}$ of the motor shaft differ from the respective variables $\omega_{\mathrm{L}}$ and $\theta_{\mathrm{L}}$, on the load side. The torsional torque equals the load torque only in the steady-state. Key parameters of the two-mass system are listed in Table I.

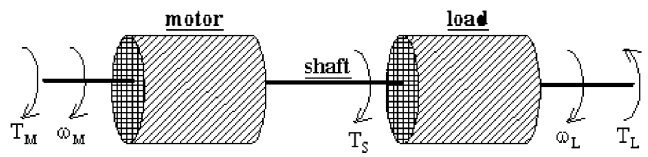

Figure 1. The plant model of the two-mass resonant system

TABLE I

NOMINAL PARAMETERS OF THE TWO-MASS PLANT

\begin{tabular}{|c|c|c|}
\hline Symbol & Quantity & Rating values \\
\hline $\mathrm{K}_{\mathrm{S}}$ & shaft stiffness & $242 \mathrm{Nm} / \mathrm{rad}$ \\
\hline $\mathrm{B}_{\mathrm{S}}$ & shaft damping coefficient & $15 \times 10^{-2} \mathrm{Nm} / \mathrm{rad} / \mathrm{s}$ \\
\hline $\mathrm{J}_{\mathrm{M}}$ & motor inertia & $641 \times 10^{-4} \mathrm{~kg} \cdot \mathrm{m}^{2}$ \\
\hline $\mathrm{B}_{\mathrm{M}}$ & $\begin{array}{c}\text { coefficient of motor } \\
\text { viscosity }\end{array}$ & $2.1 \times 10^{-3} \mathrm{Nm} / \mathrm{rad} / \mathrm{s}$ \\
\hline $\mathrm{J}_{\mathrm{L}}$ & load inertia & $523 \times 10^{-4} \mathrm{~kg} \cdot \mathrm{m}^{2}$ \\
\hline $\mathrm{B}_{\mathrm{L}}$ & coefficient of load viscosity & $5.3 \times 10^{-2} \mathrm{Nm} / \mathrm{rad} / \mathrm{s}$ \\
\hline$\omega_{\mathrm{R}}$ & natural frequency & $91.7 \mathrm{rad} / \mathrm{s}$ \\
\hline$\eta$ & damping ratio & 0.0284 \\
\hline
\end{tabular}

The state equation of the two-mass resonant system is as follows [10]:

$$
\begin{gathered}
\dot{\omega}_{M}=\frac{B_{S}}{J_{M}} \omega_{L}-\frac{B_{M}+B_{S}}{J_{M}} \omega_{M}-\frac{K_{S}}{J_{M}}\left(\theta_{M}-\theta_{L}\right)+\frac{1}{J_{M}} T_{M} \\
\dot{\omega}_{L}=\frac{B_{S}}{J_{L}} \omega_{M}-\frac{B_{S}+B_{M}}{J_{L}} \omega_{L}+\frac{K_{S}}{J_{L}}\left(\theta_{M}-\theta_{L}\right)-\frac{1}{J_{L}} T_{L} \\
\dot{\theta}_{M}=\omega_{M} \\
\dot{\theta}_{L}=\omega_{L}
\end{gathered}
$$

State variables are $\omega_{\mathrm{M}}, \omega_{\mathrm{L}}, \theta_{\mathrm{M}}$ and $\theta_{\mathrm{L}}$. Control input is the motor torque $\mathrm{T}_{\mathrm{M}}$. Output variable which can be measured is the motor speed $\omega_{\mathrm{M}}$. Controlled variable is the load speed $\omega_{\mathrm{L}}$ and disturbance $\mathrm{T}_{\mathrm{L}}$ is injected into the load. A block diagram of the compliantly coupled mechanism is shown in Fig. 2. The transfer function load is denoted $\mathrm{G}_{\mathrm{L}}(\mathrm{s})=1$ / $\left(B_{L}+s J_{L}\right)$ and the transfer function motor is denoted $G_{M}(s)=$ $1 /\left(B_{M}+s J_{M}\right)$. During transients, speeds of motor and load differ, and torsional torque is given by:

$$
\mathrm{T}_{\mathrm{S}}(\mathrm{s})=\mathrm{B}_{\mathrm{S}}\left[\omega_{\mathrm{M}}(\mathrm{s})-\omega_{\mathrm{L}}(\mathrm{s})\right]+\mathrm{K}_{\mathrm{S}}\left[\theta_{\mathrm{M}}(\mathrm{s})-\theta_{\mathrm{L}}(\mathrm{s})\right]
$$

\section{DYNAMIC ANALYSIS}

In this section various transfer functions describing the step response of the motor speed following step change in command speed and the load disturbance torque changes. The transfer functions are studied using Matlab and the step response verified by time domain simulation. The load speed and motor speed are:

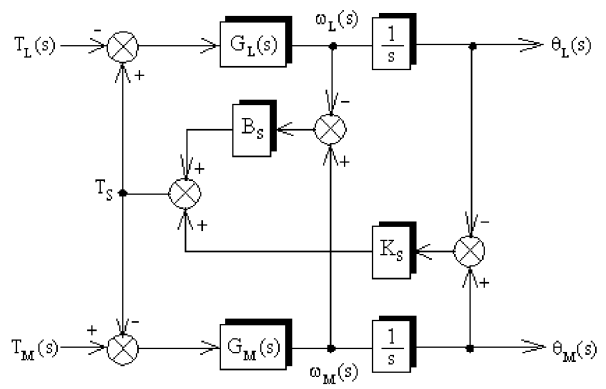

Figure 2. Block diagram of the two-mass mechanical system

$$
\begin{aligned}
& \omega_{L}(s)=\underbrace{\frac{G_{L}(s) G_{M}(s) G_{S}(s)}{1+G_{M}(s) G_{S}(s)+G_{L}(s) G_{S}(s)}}_{H_{L M}(s)} T_{M}(s) \\
& -\underbrace{\frac{G_{L}(s)\left[1+G_{M}(s) G_{S}(s)\right]}{1+G_{M}(s) G_{S}(s)+G_{L}(s) G_{S}(s)}}_{H_{L L}(s)} T_{L}(s) \\
& \omega_{M}(s)=\underbrace{\frac{G_{M}(s)\left[1+G_{S}(s) G_{L}(s)\right]}{1+G_{M}(s) G_{S}(s)+G_{L}(s) G_{S}(s)}}_{H_{M M}(s)} T_{M}(s) \\
& -\underbrace{\frac{\mathrm{G}_{\mathrm{L}}(\mathrm{s}) \mathrm{G}_{\mathrm{M}}(\mathrm{s}) \mathrm{G}_{\mathrm{S}}(\mathrm{s})}{1+\mathrm{G}_{\mathrm{M}}(\mathrm{s}) \mathrm{G}_{\mathrm{S}}(\mathrm{s})+\mathrm{G}_{\mathrm{L}}(\mathrm{s}) \mathrm{G}_{\mathrm{S}}(\mathrm{s})}}_{\mathrm{H}_{\mathrm{ML}}(\mathrm{s})} \mathrm{T}_{\mathrm{L}}(\mathrm{s})
\end{aligned}
$$

where $G_{S}(s)=B_{S}+K_{S} / s$ is transfer function of shaft. A twoinput single-output process be represented by the block diagram of the system shown in Fig. 3.

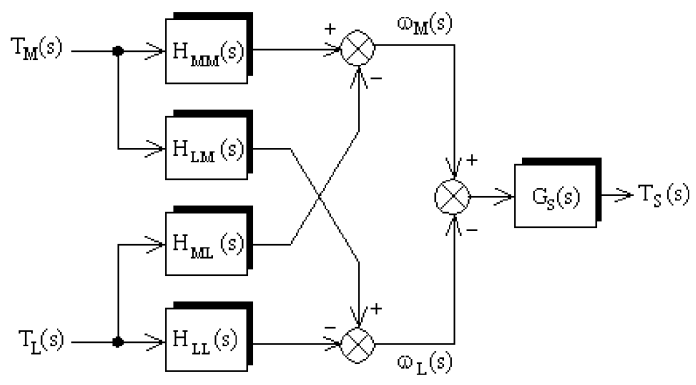

Figure 3. Two-input and single-output of the system

The transfer function from $T_{M}$ to $\omega_{M}$, which plays an important role in the closed loop design, is given by:

$$
H_{M M}(s)=\frac{\omega_{M}(s)}{T_{M}(s)}=\frac{1}{J_{L} J_{M}} \frac{J_{L} s^{2}+\left(B_{L}+B_{S}\right) s+K_{S}}{\Delta(s)}
$$

where the characteristic equation of the open loop system is given as: 


$$
\begin{gathered}
\Delta(s)=s^{3}+\left(\frac{B_{M}+B_{S}}{J_{M}}+\frac{B_{L}+B_{s}}{J_{L}}\right) s^{2} \\
+\left(\frac{K_{S}\left(J_{M}+J_{L}\right)+B_{S}\left(B_{M}+B_{L}\right)+B_{M} B_{L}}{J_{M} J_{L}}\right) s \\
+\frac{K_{S}\left(B_{M}+B_{L}\right)}{J_{M} J_{L}}
\end{gathered}
$$

Neglecting friction terms, the transfer function $\mathrm{H}_{\mathrm{MM}}(\mathrm{s})$ is given by:

$$
\mathrm{H}_{\mathrm{MM}}(\mathrm{s})=\frac{1}{\mathrm{~J}_{\mathrm{M}}} \frac{\mathrm{s}^{2}+\omega_{\mathrm{A}}^{2}}{\mathrm{~s}\left(\mathrm{~s}^{2}+\omega_{\mathrm{R}}^{2}\right)}
$$

The inertia ratio $\mathrm{K}_{\mathrm{J}}$, the mechanical resonance frequency $\omega_{\mathrm{R}}$ and the anti-resonance frequency $\omega_{\mathrm{A}}$ and are important characteristic parameters of two-mass system. For small value of $\mathrm{K}_{\mathrm{J}}$ suppress of torsional vibrations are very difficult. The control bandwidth in closed-loop motion control system is limited by the $\omega_{A}$. The value of the $\omega_{R}$ is affected by inertia ratio and depends on the drive type. An increase in the motor inertia constant decreases the $\omega_{\mathrm{R}}$ without affecting the $\omega_{\mathrm{A}}$. Conversely, increasing the mechanical stiffness of the shaft $\left(\mathrm{K}_{\mathrm{S}}\right)$ increases both $\omega_{\mathrm{R}}$ and $\omega_{\mathrm{A}}$, and also the mechanical bandwidth in closed-loop system. Therefore, in the large systems, which have large inertias, generally produce low natural frequencies. Fig. 4 show the frequency response of motor torque to motor speed (real line), shaft torque (dot line), and load speed (break line) in open-loop system.
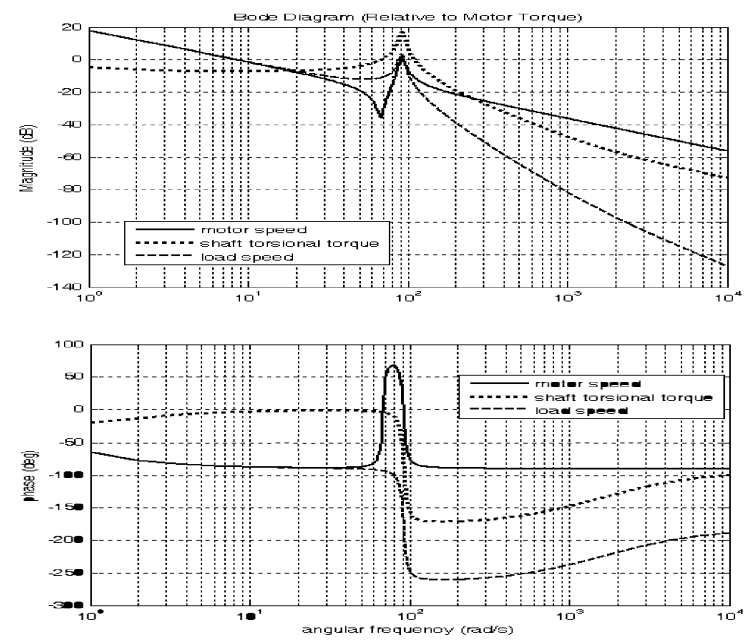

Figure 4. The response frequency of transfer function relative to motor torque

The step response of speed motor due change in torque motor torque and load torque without PID controller is shown in Fig. 5. In this figure, the dashed line and the thick solid line show corresponds relative to motor torque and relative to load torque.

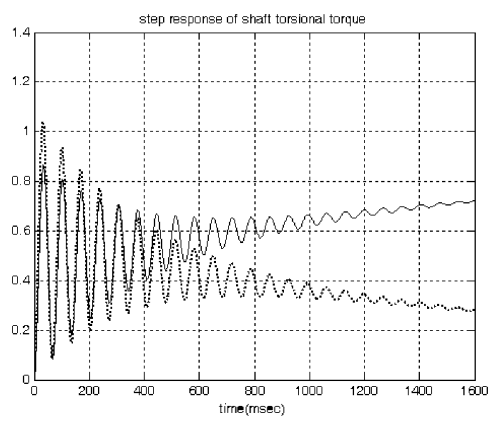

Figure 5. Step response

The dominant eigenvalues for open-loop system are shown in Table II. The resonant frequency is $\omega_{R}=91.7 \mathrm{rad} / \mathrm{s}$ and anti-resonant frequency is $\omega_{\mathrm{A}}=68.0 \mathrm{rad} / \mathrm{s}$. The damping factor of the original plant without the controller is $\eta=0.0315$. Since all eigenvalues of the system are on the left hand of the plane, the system is stable but highly damped.

TABLE II

Nominal Parameters of the Two-Mass Plant

\begin{tabular}{|c|c|c|c|c|}
\hline $\begin{array}{c}\text { Mode } \\
\text { number }\end{array}$ & Eigenvalue & Frequency & $\begin{array}{c}\text { Damping } \\
\text { ratio }\end{array}$ & Variable \\
\hline 1,2 & $-2.8905 \pm \mathrm{j} 91.6183$ & 14.5888 & 0.0315 & $\mathrm{~T}_{\mathrm{S}}$ \\
\hline 3 & -0.4734 & - & - & $\omega_{\mathrm{M}}$ \\
\hline
\end{tabular}

\section{CONTROLLER SYSTEM}

Fig. 6 show a two-mass model includes a compensation feedback controller. In conventional PID controller, $\mathrm{G}_{\mathrm{P}}(\mathrm{s})=0$ and $\mathrm{G}_{\mathrm{I}}(\mathrm{s})=\mathrm{K}_{\mathrm{P}}+\mathrm{K}_{\mathrm{I}} / \mathrm{s}+\mathrm{s} \mathrm{K}_{\mathrm{D}}$. $\Delta_{\mathrm{PID}}(\mathrm{s})$ is closed-loop characteristic equation and given by:

$$
\begin{aligned}
& \Delta_{\mathrm{PID}}(\mathrm{s})=\mathrm{s}^{4}+\underbrace{\frac{\mathrm{K}_{\mathrm{P}}}{\mathrm{K}_{\mathrm{D}}+\mathrm{J}_{\mathrm{M}}}}_{\alpha_{3}} \mathrm{~s}^{3}+\underbrace{\frac{\mathrm{J}_{\mathrm{M}} \omega_{\mathrm{R}}^{2}+\mathrm{K}_{\mathrm{I}}+\mathrm{K}_{\mathrm{D}} \omega_{\mathrm{A}}^{2}}{\mathrm{~K}_{\mathrm{D}}+\mathrm{J}_{\mathrm{M}}}}_{\alpha_{2}} \mathrm{~s}^{2} \\
& +\underbrace{\frac{\mathrm{K}_{\mathrm{P}} \omega_{\mathrm{A}}^{2}}{\mathrm{~K}_{\mathrm{P}}+\mathrm{J}_{\mathrm{M}}}}_{\alpha_{1}} \mathrm{~s}+\underbrace{\frac{\mathrm{K}_{\mathrm{I}} \omega_{\mathrm{A}}^{2}}{\mathrm{~K}_{\mathrm{P}}+\mathrm{J}_{\mathrm{M}}} \omega_{\mathrm{A}}^{2}}_{\alpha_{0}}
\end{aligned}
$$

The dynamic response of a linear system is governed by the magnitude and location of its eigenvalues, or poles. A pole-placement scheme to assign the closed-loop poles of the characteristic equation is proposed. The CDM used for design the optimum controllers' gains. With compared the polynomial coefficients of characteristic equation in PID controller and CDM the PID controller's gains can be found as following [11]: 


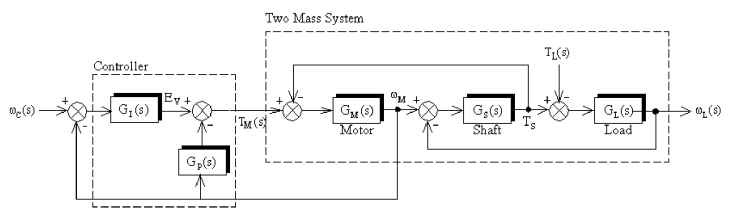

Figure 6. Speed PID controller with compensation for two-mass system

$$
\left\{\begin{array}{l}
\mathrm{K}_{\mathrm{I}}=\frac{\mathrm{K}_{\mathrm{S}} \gamma_{3}}{\gamma_{1} \gamma_{2} \gamma_{3}-\gamma_{1}-\gamma_{3}} \\
\mathrm{~K}_{\mathrm{D}}=\frac{\mathrm{J}_{\mathrm{L}} \gamma_{1}}{\gamma_{1} \gamma_{2} \gamma_{3}-\gamma_{1}-\gamma_{3}}-\mathrm{J}_{\mathrm{M}} \\
\mathrm{K}_{\mathrm{P}}=\frac{\gamma_{1} \gamma_{3} \sqrt{\mathrm{K}_{\mathrm{S}} \mathrm{J}_{\mathrm{L}}} \sqrt{\gamma_{2}}}{\gamma_{1} \gamma_{2} \gamma_{3}-\gamma_{1}-\gamma_{3}}
\end{array}\right.
$$

Fig. 7, 8 and 9 show the locus of the roots the closed-loop system for change gains of controller. We see that for change in controller gains the system is stable.

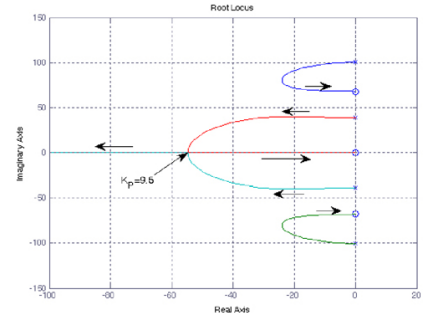

Figure 7. Locus of the roots of the closed-loop system for change proportional gain of controller

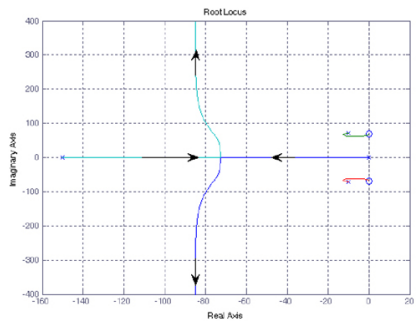

Figure 8. Locus of the roots of the closed-loop system for change integral gain of controller

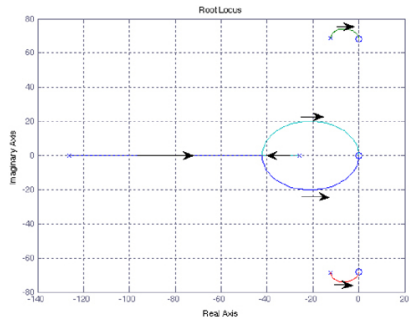

Figure 9. Locus of the roots of the closed-loop system for change derivative gain of controller

\section{Simulation RESUlTS}

The quality of two-mass system can be evaluated by characteristics of transient response. In this section various transfer functions describing the step response of the motor speed following step change in command speed and disturbance torque are derived. The transfer functions are studied using Matlab and the step response verified by time domain simulation. The zeros of the closed-loop transfer functions that relate the command speed to motor speed, is dependent on not only the $\omega_{\mathrm{A}}$ but also the choice of speed control methods. The stability indexes of the CDM controller are the same used in simulation: $\gamma_{1}=4, \gamma_{2}=2, \gamma_{3}=1$ and $\gamma_{4}=4$.

The simulation results of shaft torque, motor torque and motor speed due to unit-step command speed when the twomass system is compensated by the conventional PID controller, I-PD controller and proposed MPID controller show in Fig. 10. We see that I-PD controller the response of the shaft torque is with a very large overshoot. Figs. 11 show the frequency response of the close-loop system for three controllers.

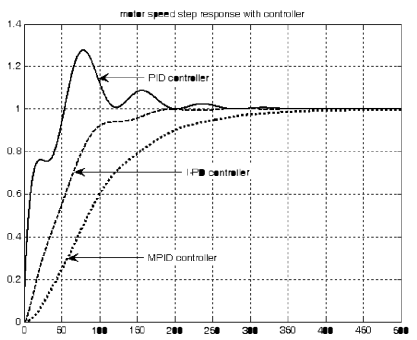

Figure 10. Step response of motor speed with controller
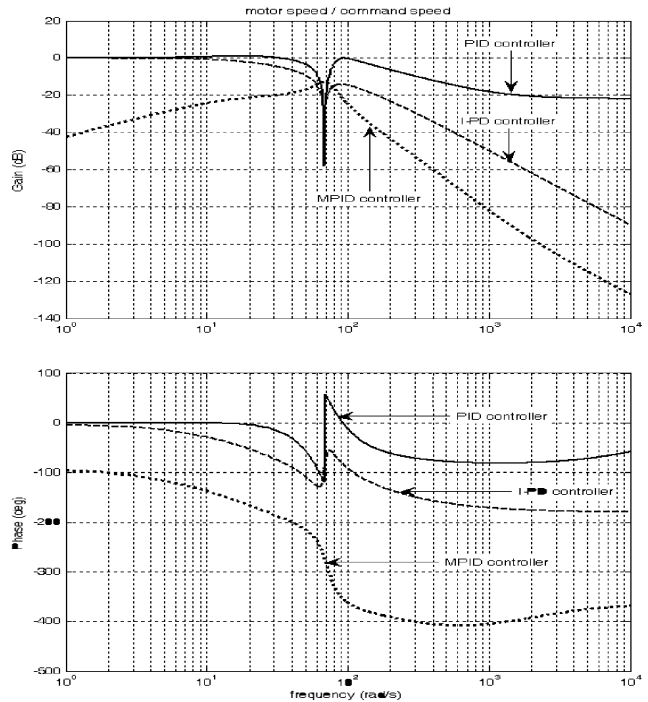

Figure 11. Frequency response of motor speed with controller 


\section{CONCLUSION}

In this paper a systematic dynamic analysis of two mass resonant systems is presented by deriving the small signal plant and speed control model. The effectiveness of the three-kinds of speed control loop was analyzed by considering the linearized model. The response of the system is studied for command speed and the load disturbance torque changes. The analysis is validated by time domain simulation. Analysis and simulation results are illustrated to verify good performance obtained using the proposed controller.

\section{REFERENCES}

[1] M.R. Yousefi, G. Shahgholian, A. Etesami, P. Shafaghi, "Small signal modeling and analysis of control speed for two mass resonant system", IEEE/IPEC, pp. 1000-1003, Singapore, Oct. 2010.

[2] K. Peter, I. Scholing, B. Orlik, "Robust output feedback $\mathrm{H}_{\infty}$ control with a nonlinear observer for a two-mass system", IEEE Trans. Ind. Appl., Vol.6, No.2, pp.637-644, 2003.

[3] T. Orlowska-Kowalska, K. Szabat, "Neural network application for mechanical variables estimation of a two-mass drive system", IEEE Tran. Ind. Electron. Vol.54, No.3, pp.1352-1364, Apr. 2007.

[4] G. Zang, J. Furusho, "Speed control of two-Inertia system by PI/PID control," IEEE Trans. Ind. Elec., Vol.47, No.3, pp.603-609, June 2000
[5] S. Suathed, S. Nundrakwang, T. Benjanarasuth, J. Ngamwiwit, N Komine, "Simplified design of I-P controller for speed of two-inertia system", IEEE Tran. on Cont. Sys., Vol.27, No.1, pp.1900-1904, Jan. 2008.

[6] T.M. O'Sullivan, C.M. Bingham, N. Schofield, "High performance control of dual-inertia servo drive systems using low cost integrated SAW torque transducers", IEEE Tran. on Indu. Elec., Vol.55, No.4, pp.1226-1237, Aug. 2006.

[7] B. Nam, H. Kim, H. Lee, D. Kim, "Optimal speed controller design of the two-inertia stabilization system", PWASET Vol.31, pp.155-160, July 2008.

[8] S.N. Vukosavic, M.R. Stojic, "Suppression of torsional oscillations in a high performance speed servo drive," IEEE Trans. Ind. Elec., Vol.45, No.1, pp.108-117, 1998.

[9] S. Morimoto, M. Ohashi, Y. Takeda, K. Tanigchi, "High performance speed control for torsional system based on $\mathrm{H}_{\infty}$ control theory", IEEE/PEDS, Vol.2, pp.828-833, Feb. 1995.

[10] G. Shahgholian, J. Faiz, "An analytical approach to synthesis and modeling of torque control strategy for two-mass resonant systems", Inte. Revi. of Auto. Cont. (IREACO), Vol.2, No.4, pp.459-468, July 2009.

[11] G. Shahgholian, J. Faiz, P. Shafaghi, "Analysis and simulation of speed control for two-mass resonant system", IEEE/ICCEE, pp.668672, Dec. 2009 